\title{
Sağlık Çalışanlarında Öznel İyi Oluşun Duygusal Emek Davranışı Üzerine Etkisi ${ }^{1}$
}

\author{
DOI: $10.26466 /$ opus.663474
}

\author{
$*$

\section{Bünyamin Özgüleș} \\ * Dr, Yunus Emre Devlet Hastanesi, Eskişehir/Türkiye \\ E-Posta: bunyas32@yahoo.com \\ ORCID: 0000-0002-8401-3620 \\ ** Dr.Öğr. Üyesi, Sağlık Bilimleri Üniversitesi, Sağlık Bilimleri Fakültesi, İstanbul/Türkiye \\ E-Posta : $\underline{\text { aliarslanoglu18@gmail.com }}$ \\ ORCID: $\underline{000-0002-4454-0397}$
}

\section{Öz}

Araştırmanın amacı sağlık çalışanları özelinde öznel iyi oluş alt boyutları ile duygusal emek alt boyutları arasında ilişkileri ve etkileri belirlemekti. Çalışmada ilişkisel tarama tekniği ile anket yöntemi kullanılmıştır. Daha önceden geçerlilik ve güvenirliliği yapılmış olan ölçeklerden dizayn edilen anket kullanılmıştır. Araştırma Ankara ilinde faaliyet gösteren özel bir hastanede çalışan 235 kişi ile yapılmıştır.Katılımcıların çoğunluğu kadın (\%68,9), Diğer meslek grubu (\%43), 35 yaş altı (\%66), \%51,9'unun evli olduğu, \%54,1'inin ilköğretim/lise mezunu, \%60,7'sinin 10 yıl altında hizmet süresinde olduğu görülmektedir. Ölçek toplamının 48 maddesine Cronbach Alpha güvenirlik testi uygulanmıştır. Sonuç olarak öznel iyi oluş ölçeğinin değeri 0,761; duygusal emek ölçeğinin değeri 0,825 ve genel ölçeğin değeri ise 0,778 bulunmuştur.Yapılan araştırma neticesinde Değiş̧kenler arası ilişkiler incelendiğinde ise Samimi davranışar ile pozitif duygulanım arasında $(r=0,188, p<0,01)$ istatiksel anlamda anlaml pozitif, doğrusal ve zayıf bir ilişki vardır. Diğger değgişkenler arası anlamlı bir ilişki tespit edilememiştir. Samimi davranışın yaşam doyumu ile pozitif duygular arası regresyon katsayılarının ise anlamlı olduğu görülmüştür.

Anahtar Kelimeler: Öznel İyi Oluş, Duygusal Emek, Pozitif Duygulanım, Negatif Duygulanım, Yaşam Doyumu

\footnotetext{
1 Bu çalışma 20-23 Haziran 2019 tarihinde istanbul Üsküdar Üniversitesinde gerçekleştirilen 4. Uluslararası Sağlık Bilimleri Ve Yönetim Kongresinde sözlü sunum olarak sunulmuştur.
} 


\title{
The Effect of Subjective Well-Being on Emotional Labor in Healt Employees
}

\begin{abstract}
The aim of this research is to determine the relationships and effects between sub-dimension of subjective well-being and sub-dimensions of emotional labor for the health workers. In this study, relational scanning technique and questionnaire method were used. The used questionnaire is derived from other research that had been reliable and valid. The study was conducted with 235 employees working in a private hospital in Ankara. Following findings most of the participants were female (68.9\%), other occupational group is $43 \%$, under age of 35 is $66 \%, 51.9 \%$ were married, $54.1 \%$ were primary/high school graduates, $60.7 \%$ were is under 10 years of service. Cronbach Alpha reliability test was applied to 48 items of the scale. So, the value of subjective well-being scale is 0.761 ; The value of the emotional labor scale is 0.825 and the value of the general scale is 0.778 . Relationships between the variables showed that there was a statistically significant positive, linear and weak relationship between intimate behavior and positive emotions $(r=0.188, p<0.01)$. A statistically significant positive, linear and weak relationship There is no significant relationship between the other variables. Regression coefficients between life satisfaction and positive emotion were found to be significant.
\end{abstract}

Keywords: Subjective Well-Being, Emotional Labor, Positive Emotion, Negative Emotion, Life Saturation. 


\section{Giriş}

Tüm insanlar gibi sağlık çalışanları da gerek özel yaşamında gerekse iş yaşamında uyarıcılara farklı tepki verebilmekte farklı davranış durumları sergileyebilmektedir. Bu durum büyük ölçüde insanın genel yaşam doyumu ve pozitif negatif duygulanım durumlarından ayrıca iş yerinde oluşan iş yaşamında oluşan öznel iyi oluşundan kaynaklanmaktadır. Çalışanların duygu durumlarının önemli olduğu sağlik hizmetlerinin sunumunun her aşamasında sağlık çalışanlarının öznel iyi oluş ve duygusal emek düzeyleri etkili olmaktadır. Yapılan çalışmalarda öznel iyi oluş seviyeleri yüksek olan bir başka deyişle mutlu olan bireylerde kişiler arası iletişim geliştiği; Yaşama enerjisinin, üretkenliğin, yaşam kalitesinin, ve iş ortamlarında başarıların arttı̆̆1 saptanmıştır (Doğan ve Eryılmaz, 2012, s.383). Daha genel bir ifade ile öznel iyi oluş seviyeleri yüksek olan çalışanların kurumların istediği şeklinde davranma durumu olan duygusal emek davranışlarını daha belirgin olarak ve istenildiği şekliyle göstermeleri beklenmektedir. Aksi halde bu tarz pozitif davranışların yerini sinizm gibi negatif duygulanımların alması kaçınılmaz olmaktadır. Özellikle sağlık sektöründe, hasta güvenliği kültürünün oluşumuna, negatif davranışların, kurumlara zarar ve tehdit oluşturacağ1 düşünülmektedir (Keçeli, 2019, s.189). Bu araştırmanın temel amaçlarından biriside bu iki değişken arasındaki ilişki ve etki düzeylerinin incelenmesidir. Bu bağlamda çalışanların ve yöneticilerin bu konulardaki bilinç düzeylerinin artması çalışanların sağ lığına mutluluğuna, başarısına, dolayısı ile işyerlerindeki verdikleri hizmet kalitesine olumlu yönde etki edeceği düşünülmektedir. Bu bilgiler çerçevesinde bu araştırmada Ankara İlinde faaliyet gösteren özel hastane çalışanları örnekleminde sağlık çalışanlarının öznel iyi oluş ile duygusal emek düzeyleri ne seviyede ve bu iki değişken arasındaki ilişki ve etki durumları ne düzeyde olduğunun araştırılması araştırmanın ana hipotezlerindendir.

\section{Öznel İyi Oluş}

On dokuzuncu yüzyılın başlarında psikoloji bilimi alanında çalı̧̧ma yapan araştırmacılar depresyon ve kaygi gibi olumsuz duygular alanında araştırma yaparken, olumlu duygulara fazla dikkat etmemişlerdir. Özellikle pozitif psikolojinin gelişmesi ile birlikte öznel iyi oluş konularında yapılan ça- 
lışmalar artış göstermiştir. Öznel iyi oluş kavramı kişiler için genellikle birbirleriyle ilişkili, pozitif duyguların varlı̆ğ negatif duyguların azlığı ve yaşam doyumunun varlığı şeklinde tanımlanmaktadır (Myers ve Diener, 1995, s.11). Öznel iyi oluş, bireyin yaşamını değerlendirmesi ve yargı bildirmesi anlamina gelmektedir. Olumlu duygulanım, olumsuz duygulanım ve yaşam doyumu olmak üzere üç alt boyutlu bir yapı göstermektedir (Diener, 1984). Olumlu duygulanım, güven, ilgi, ümit, güçlü, heyecan, gurur, heves, neşe gibi duyguları ifade ederken olumsuz duygulanım ise öfke, nefret, suçluluk, sinirli, tedirgin, üzüntü gibi olumsuz duyguları içerir. Yaşam doyumu boyutu ise, genel olarak yaşamdan memnuniyeti belirtmekte ve öznel iyi oluşun bilişsel bileşenini oluşturmaktadır. Bireyin çeşitli sosyal ve yaşam alanlarındaki doyumlarına ilişkin değerlendirmeleri yansıtır (Myers ve Deiner, 1995, s.11).

Yapılan araştırmalarda öznel iyi oluş seviyeleri yüksek olan bir başka deyişle mutlu olan bireylerde kişiler arası iletişim geliştiği; Yaşama enerjisinin, üretkenliğin ve yaşam kalitesinin, yaşam sürelerinin arttığı ve iş ortamlarında başarılı olunduğu saptanmıştır (Doğan ve Eryılmaz, 2012, s.383). Araştırmacılar psikolojik iyi oluş halinin birey açısından pek çok olumlu sonuç yaratacağı ile ilgili önemli bulgular elde etmişlerdir. Örneğin psikolojik durumlar açıdan iyi olan çalışanların, iş ve özel yaşam tatminleri, fiziksel ve zihinsel sağlıkları, kendilerine güvenleri, motivasyonları ve olumlu düşünme güçlerinin daha fazla olması beklenmektedir (Deneve ve Cooper, 1998.den Aktaran Akdoğan ve Polatçı, 2013, s.278). Bu durumun çalışanların hem kendilerine hem de çalıştıkları kurumlara olumlu etki etmesi beklenmektedir.

\section{Duygusal Emek}

Duygusal emek kavramı literatürde ilk olarak Amerikalı sosyolog Arlie Russel Hochschild'in kullandığı ve literatüre kazandırdığı görülmektedir. Duygusal emeği Hoschcshild (1983, s.7), "The Managed Heart" adlı eserinde "işin gereklerine uyum sağlayabilmek amacıyla açık bir yüz ve bedensel ifade oluşturabilmek için hislerin yönetimi" olarak ifade etmektedir. Hochschild (1983), duygusal emeğin yüzeysel ve derin davranışlar şeklinde alt boyutları altında gösterileceğini belirtmiş ve genellikle duygusal emeğin olumsuz sonuçları üzerine odaklanmıştır. Ashforth ve Humphrey $(1993$, s.88) ise duygusal 
emeği, "hizmet sürecinde, örgüt tarafindan arzu edilen duygularm müşteriye yansttılması" olarak tanımlamışlardır. Hizmet sektöründe çalışan kişilerin müşterileri ile iletişim halinde güler yüzlü olması veya bir polisin bir suçluyu yakalarken ki yüz ifadesinin asık olması duygusal emeğe gösterilebilecek örneklerdendir. Bu şekilde davranış göstermek bir bakıma rol yapma şeklinde olur fakat insanlar bazen içlerinden geldikleri gibi de hareket edebilmektedirler. İşte bu durumda Ashforth ve Humphrey (1993), duygusal emeğe doğal davranış boyutunu eklemiş ve çalışanlar duygusal emek davranışı sergilerken içlerinden geldiği gibi davranabilmektedirler şeklinde yorumlamışlardır. Ayrıca duygusal emeğin olumlu sonuçlarının da olabileceği görüşünü öne sürmüşlerdir. Morris ve Feldman (1996, s.987), tarafından duygusal emek, "insanlar arasındaki etkileşimler esnasinda örgütün istediği duyguyu göstermek için gereken çaba, plan ve kontrol" olarak tanımlanmıştır. Bu çabanın gösteriminde çalışanlar sanki yüzlerine bir maske takmış gibi sahte davranıs sergilemektedirler. Morris ve Feldman, (1996) duyguların anlık olarak durumlara göre değişebileceğini ve bu sebepten dolayı da sergilenen duygusal emek düzeyinde değişiklik gösterebileceğini vurgulamaktadır. Ayrıca duygusal emeği dört boyutta ele almışlardır. Bunlar; duygusal davranış gösterimindeki sıklık, davranış kurallarında gösterilen dikkat, sergilenmesi gereken duyguların çeşitliliği ve duygusal çelişkidir Yine aynı araştırmacı duygusal emek boyutlarını etkileyen çeşitli değişkenler üzerinde durmuştur. Bu değişkenler, örgütsel özellikler, bireysel özellikler ve iş ile ilgili özellikler olarak ele alınmıştır (Morris ve Feldman, 1996, s.994). Son olarak Grandey, (2000) yılında yaptığı araştırmada kendinden önceki duygusal emek çalışmalarını ve yaklaşımlarını ele almış ve ortak bir sonuç çıkarmayı hedeflemiştir. Bu kapsamlı çalışmada duygusal emeğin neleri etkilediği ve nelerden etkilendiği bir model etrafında gösterilmiştir. Duygusal emeği, iş görenlerin kurumun göstermesini istediği davranışları göstermek amacı ile duygu durumunu düzenleme çabası, gayreti, emeği ve süreci olarak ifade etmiştir (Uzuntarla, 2015, s.48).

\section{Öznel İyi Oluş ve Duygusal Emek Davranışı Arasındaki İlişkiler}

Konu ile ilgili kapsamlı bir literatür taraması yapıldığında bu iki değişkenin bir arada ele alan çalışmaya rastlanmamıştır. Duygusal emeğin bağımlı, bağımsız, düzenleyici ve arac gibi çok çeşitli değişkenlerle ele alındığı bir- 
çok çalı̧̧ma mevcuttur. Duygusal emek kavramının birçok değişkeninin olması çok boyutlu olması sebebiyle tek bir çalışmayla konu hakkında bilgi sahibi olmak neredeyse imkânsızdır. Bu gerçeklikten hareketle bu araştırmada duygusal emeği etkileyen olası faktörler incelenmek istenmiştir. Kuramsal olarak araştırmanin teorik alt yapısı Grandey (2000)' nin duygusal emek modeline göre temellendirilmiştir. Bu model incelendiğinde duygusal emeği etkileyen duygusal olaylar bireysel ve örgütsel faktörlerin olduğu görülmektedir. Duygusal olaylar açısından Kızanıklı, (2014, s.61) tarafından yapılan çalışmada bağımsız değişkenler olan olumlu ve olumsuz davranış kuralı algıları ile bağımlı değişken olan duygusal emek davranışı arasında pozitif yönlü bir ilişki olduğu görülmüştür. Ayrıca Duygusal olaylar, pozitif olaylar, negatif olayların derinlemesine rol yapma yüzeysel rol yapmayı etkilediği sonucuna ulaşılmıştır. Grandey, (2000)' e göre duygu durumları her zaman çalışanların iş davranışlarını yani duygusal emeklerini etkilemiştir. Son zamanlarda duyguların ve bireysel faktörlerin çalışma yaşamındaki rollerini (duygusal emek) inceleyen çalışmalarda artmaktadır. Duygusal emek davranışını bağımlı değişken olarak alıp duygusal zekâ ve duygusal olaylar ile (Polatçı, 2015, s.146), (Yalçın 2010, s.35), (Savaş, 2012, s.117) Duygular ile (Seçer, 2005), Demografik faktörler ve kişilik özellikleri ile ilgili de (Beğenirbaş, 2013), (Değirmenci 2010, s.30), tarafından çeşitli sektörlerde uygulamaları yapılan çalışmalar yapılmıştır. Bu çalışmalar ışı̆̆ında öznel iyi oluş kavramı ile duygusal olaylar ve bireysel farklılıklar çok yakın ilişkide olduğu için ve literatürde bu iki değişken arasındaki ilişkiyi inceleyen başka çalışma olmadığı için ayrıca literatürdeki boşluğu dolduracağı düşüncesi bu araştırmanın temel çıkış noktasıdır.

\section{Yöntem}

\section{Araştırmanın Amacı, Evreni ve Örneklemi}

Araştırmanın amacl; öznel iyi oluşun alt boyutlarının duygusal emeğin alt boyutları üzerine etkisini daha ayrıntılı bir şekilde araştırmaktır. Bu amaç ile iki aşamalı bir araştırma tasarlanmıştır. İlk olarak kavramlara ait konuları anlamak için keşfedici bir araştırma yürütülmüş. İkinci aşamada ise, ölçek maddelerindeki sorular için yanıtlar aranmıştır. Elde edilen bulgular çeşitli istatistiksel programlar aracılığı ile analiz edilmiştir. 
Araştırmanı evreni Ankara ilinde faaliyet gösteren bir özel hastanede çal1şan sağlık personeli oluşmaktadır. Örneklem olarak ise örneklem seçimine gidilmeden tam sayım metodu yöntemi ile tüm çalışanlara ulaşılmaya çalışılmıştır. Eylül -Aralık 2018 tarihinde Özel hastanede görev yapan sağlık çalışanlarından 413 kişiye ulaşılmış ancak 250 kişi araştırmaya katılmayı kabul etmiştir. Cevaplanmak üzere verilen anket formlarından 15 tanesi eksik ve yanlı doldurduğu düşüncesiyle veri setinden çıkarılmış ve 235 anket araştırmaya dâhil edilmiştir.

\section{Araştırmanın Modeli ve Hipotezleri}

Araştırmanın bu aşamasında; araştırmaya ait değişkenleri, modeli, evren ve örneklem durumunu, araştırmanın hipotezlerini ve veri toplama tekniği ile ilgili bilgilere yer verilmiştir.

\section{Araştırmanın Modeli}

Çalışmada öznel iyi oluşun alt boyutlarının duygusal emeğin alt boyutlarını etkilediği şeklinde teorik bir model geliştirilerek test edilmek istenmiştir.

\section{Araştırmanın Değişkenleri}

Araştırmanın bağımsız değişkenleri öznel iyi oluşun etkilerini ölçen yaşam doyumu, pozitif duygular ve negatif duygular değişkenlerinden oluşmaktadır. Araştırmanın bağımlı değişkeni ise duygusal emeğin alt boyutları olan samimi davranış, derin davranışlar ve yüzeysel davranışlardır.

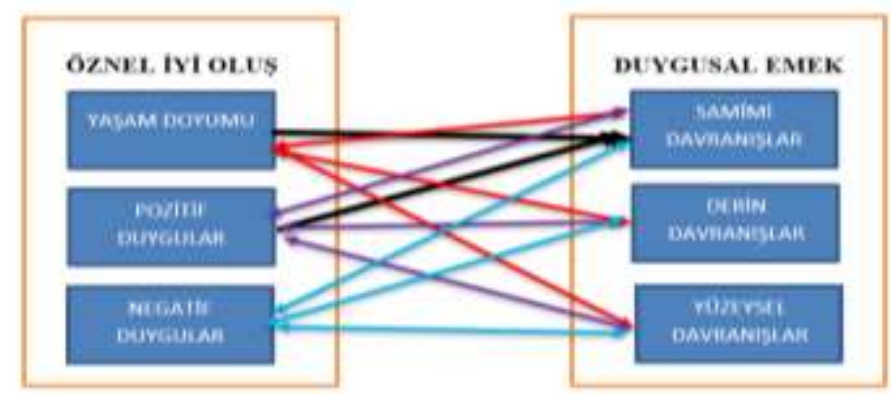

Şekil 1. Araştırma Modeli 


\section{Araştırmanın Hipotezleri}

Araştırma ilişkisel tarama yöntemi kullanılarak anketlerden elde edilen veriler analiz edilerek elde edilen veriler ve sonunda hipotezlerin gerçekleşme durumlarına göre yöneticilere ve çalışanlara çeşitli önerilerde bulunulacaktır. Bu bağlamda araştırmadaki temel hipotezlerimiz şu şekilde şu şekilde planlanmıştır.

- H1: Yaşam doyumu ile yüzeysel davranış arasında anlamlı bir ilişki bulunmaktadır.

- $\mathrm{H}_{2}$ : Yaşam doyumu ile derin davranış arasında anlamlı bir ilişki bulunmaktadır.

- H3: Yaşam doyumu ile samimi davranış arasında anlamlı bir ilişki bulunmaktadır.

- $\mathrm{H}_{4}$ : Olumlu duygulanım ile yüzeysel davranış arasında anlamlı bir ilişki bulunmaktadır.

- H5: Olumlu duygulanım ile derin davranış arasında anlamlı bir ilişki bulunmaktadir.

- H6: Olumlu duygulanım ile samimi davranış arasında anlamlı bir ilişki bulunmaktadır.

- $\mathrm{H}_{7}$ : Olumsuz duygulanım ile yüzeysel üzerinde arasında anlamlı bir ilişki bulunmaktadır.

- H8: Olumsuz duygulanımın ile derin davranış arasında anlamlı bir ilişki bulunmaktadır.

- H9: Olumsuz duygulanımın ile samimi davranış arasında anlamlı bir ilişki bulunmaktadır.

- H10: Yaşam doyumunun samimi davranış üzerinde anlamlı bir etkisi bulunmaktadır.

- H11: Olumlu Duygulanımın samimi davranış üzerinde anlamlı bir etki bulunmaktadır.

\section{Veri Toplama Araçları}

Anket, katılımcılar için araştırma hakkında bilgi vermek üzere ve aydınlatılmış onamı da içeren tanıtım yazısı ve ölçek maddelerinden oluşmaktadır. Birinci bölümde katılımcıların sosyo-demografik özelliklerini kapsayan 6, 
ikinci bölümde öznel iyi oluş ile ilgili 25, üçüncü bölümde ise duygusal emekle ilgili 13 madde yer almaktadır.

Öznel İyi Oluş Ölçeği; Öznel iyi oluş bilişsel ve duygusal iki bileşenden oluştuğu için ölçümünde iki ölçek kullanılmaktadır. İlki yaşam doyumu ölçeğidir ikincisi ise olumlu-olumsuz duygulanım ölçeğidir. Yaşam Doyumu Ölçeği Diener ve arkadaşları (1985) tarafından geliştirilmiş olup Köker (1991) tarafından Türkçe'ye uyarlama çalışması yapılmıştır. Toplam beş maddeden oluşan ölçek, Likert tipinde 1-7 arasında puanlanmaktadır. Yaşam Doyumu Ölçeği'nde seçeneklerin değerleri toplanarak toplam puanı elde edilmektedir. Pozitif- Negatif Duygu Ölçeği, Watson ve arkadaşları (1988) tarafından geliştirilmiş ve Gençöz (2000), tarafından Türkçe'ye uyarlaması yapılmıştır. Ölçek on adet olumlu, on adet olumsuz duyguyu ölçen maddeler içermektedir ve 5'li likert tipinde değerlendirilmektedir. Ölçeğin uyarlama çalışmalarında, Cronbach Alfa iç tutarlık katsayısı Negatif Duygu için. 0,83, Pozitif Duygu için 0.86 dır (Gençöz, 2000). Ölçekteki olumlu ve olumsuz duygu durumu puanları ayrı ayrı hesaplanmıştır.

Çalışanların duygusal emeğini değerlendirmek amacıyla Diefendorff, Croyle ve Gosserland (2005, s.339-340) tarafından geliştirilmiş ve Türkçeye uyarlaması Basım ve Beğenirbaş (2012, s.77) tarafindan yapılan “Duygusal Emek Ölçeği" kullanılacaktır. Duygusal emek ölçeği, Diefendorff, Croyle ve Gosserand, (2005, s.339-340) tarafindan, Grandey (2003, s.86) ve Kruml ve Geddes'ın (2000, s.8) duygusal emek ölçeklerinin bazı maddeleri alınarak uyarlanması ve bazı maddelerin ise geliştirilmesiyle oluşturulmuştur. Ölçek, yüzeysel rol yapma alt boyutu (6 madde1-6.sorular), derinden rol yapma alt boyutu (4 madde 7-10. sorular) ve samimi duygular alt boyutu (3 madde 11-13. sorular) olmak üzere üç ayrı alt boyuttan oluşmaktadır. Katılımcılar ölçek maddelerini beşli likert tipi yardımıyla puanlamışlardır (1=Hiçbir Zaman, 5= Her Zaman).

\section{Araştırmanın Sınırlıklan}

Her Araştırmanın olduğu gibi bu araştırmada da çeşitli sınırlılıklardan bahsedilebilir bu kapsamındaki sınırlılıklar: Araştırmanın Ankara ilinde faaliyet gösteren özel hastane çalışanları üzerinde yapılmış olması kapsam yönünden sınırlılık olarak ifade edilebilir. Ayrıca belli bir zaman aralığında yapıl- 
mış olması ve anketi cevaplayan katılımcıların yanlı cevap vermiş olmaları olasılı̆̆ıda da ayrı bir sınırlılık olarak ifade edilebilir.

\section{Bulgular}

Araştırmanın analizi ve bulguları kısmında yapılan analizler çerçevesinde katılımcların sosyo-demografik özellikleri ile bulgular, farklılık analizlerine ait sonuçlar ve ilgili değişkenlere ait korelasyon ve analizler ve değişkenlerin regresyon sonuçları paylaşılmıştır.

\section{Katılımcıların Demografik Özelliklerine İlişkin Bulgular}

Katılımclara ait demografik özellikler ile ilgili bulgular kısmında, anket yapmayı katılmayı kabul eden gönüllülerin cinsiyet, medeni durum, yaş, eğitim durumu, hizmet süresi ve meslekleri ile ilgili bilgiler incelenmiş, her değişkene ait frekans ve yüzde değerleri belirtilmiştir.

Tablo 1. Katılımcıların Sosyo-Demografik Özellikleri

\begin{tabular}{|c|c|c|c|}
\hline Değişken & & $\mathbf{n}$ & $\%$ \\
\hline \multirow{4}{*}{ Cinsiyet } & Kadın & 162 & 68,9 \\
\hline & Erkek & 70 & 29,8 \\
\hline & Cevapsiz & 3 & 1,3 \\
\hline & Toplam & 235 & 100 \\
\hline \multirow{4}{*}{ Medeni Durum } & Evli & 122 & 51,9 \\
\hline & Bekar & 108 & 46,0 \\
\hline & Cevapsiz & 5 & 2,1 \\
\hline & Toplam & 235 & 100 \\
\hline \multirow{6}{*}{ Yaş } & $<26$ & 81 & 34,5 \\
\hline & $26-35$ & 74 & 31,5 \\
\hline & $36-45$ & 49 & 20,8 \\
\hline & 46 ve üzeri & 26 & 11,1 \\
\hline & Cevapsız & 5 & 2,1 \\
\hline & Toplam & 235 & 100 \\
\hline \multirow{7}{*}{$\begin{array}{l}\text { Öğrenim } \\
\text { Durumu }\end{array}$} & İlköğretim/Lise & 127 & 54,1 \\
\hline & Ön lisans & 60 & 25,5 \\
\hline & Lisans & 24 & 10,2 \\
\hline & Yüksek lisans & 8 & 3,4 \\
\hline & Doktora & 10 & 4,3 \\
\hline & Cevapsiz & 6 & 2,5 \\
\hline & Toplam & 235 & 100 \\
\hline
\end{tabular}




\begin{tabular}{llll}
\hline \multirow{3}{*}{ Hizmet süresi } & $0-10$ yıl & 158 & 67,2 \\
\cline { 2 - 4 } & $11-20$ yıl & 46 & 19,6 \\
\cline { 2 - 4 } & 21 ve üstü yıl & 26 & 11,1 \\
\cline { 2 - 4 } & Cevapsiz & 5 & 2,1 \\
\cline { 2 - 4 } & Toplam & $\mathbf{2 3 5}$ & $\mathbf{1 0 0}$ \\
\hline \multirow{4}{*}{ Meslek } & Doktor & 24 & 10,2 \\
\cline { 2 - 4 } & Hemşire & 63 & 26,8 \\
\cline { 2 - 4 } & Sağllk teknikeri/teknisyeni & 44 & 18,7 \\
\cline { 2 - 4 } & Diğger & $\mathbf{3}$ & 43,0 \\
\cline { 2 - 4 } & Cevapsiz & $\mathbf{1 , 3}$ \\
\cline { 2 - 4 } & Toplam & $\mathbf{2 3 5}$ & $\mathbf{1 0 0}$ \\
\hline
\end{tabular}

Tablo incelendiğinde; \%68,9'unun kadın ve \%29,8'inin erkek olduğu, \%51,9'unun evli olduğu, \%66 sının 35 yaş altında olduğu, \%54,1'inin ilköğretim/lise mezunu, \%60,7'sinim 10 yıl altında hizmet süresinde olduğu, \%43 ünün diğer meslek grubunda olduğu görülmektedir.

\section{Ölçeklerin Güvenirlilik Analizleri}

Araştırmanın bu kısmında araştırmada verileri toplamak amacıyla kullanılan ölçeklerin toplam güvenirlilik analizleri yapılmıştır.

$\mathrm{Bu}$ araştırmada kullanılan ölçeklerin güvenirlilikleri analizleri tablo 2 de sunulmuştur.

Tablo 2. Kullanılan Ölçeklerin Güvenirlilik Sonuçları

\begin{tabular}{lll}
\hline Kullanılan ölçekler & Cronbach's alfa & Madde sayısı \\
\hline Öznel iyi oluş ölçeği &, 761 & 25 \\
\hline Duygusal emek ölçeği &, 825 & 13 \\
\hline Genel & $\mathbf{7 7 8}$ & $\mathbf{4 8}$ \\
\hline
\end{tabular}

Ölçeğin toplamda 48 maddesine Cronbach Alpha güvenirlik testi uygulanmıştır. Sonuç olarak öznel iyi oluş ölçeğinin değeri 0,761 değerinde duygusal emek ölçeğinin 0,825 değerinde ve genel ölçeğin toplam değerinin ise 0,778 olduğu görülmüştür. Buna göre ölçeğin güvenilir olduğu söylenebilir.

\section{Değişkenler Arası İlişkiler}

İki değişken arasındaki korelasyon katsayısı, aralık ve rasyo düzeyinde ölçülen iki değişken arasındaki ilişkinin ya da bağımlılığın olup olmadığı- 
nı varsa yönü ve gücünü göstermek amacıyla yaygın olarak kullanılan bir analiz tekniğidir. Analiz sonucunda hesaplanan "korelasyon kat sayısı" " $r$ " ile gösterilir. Korelasyon katsayısı $r-1$ ile +1 arasında bir değer alır (Yazıcıoğlu ve Erdogan, 2014, s.335).

Tablo incelendiğinde yüzeysel davranışlar ile derin davranışlar arasinda $(\mathrm{r}=0,379, \mathrm{p}<0,01)$ istatistiksel olarak anlamlı pozitif, doğrusal ve zayıf bir ilişki, samimi davranışlar arasında $(r=-0,144, p<0,05)$ istatistiksel olarak anlamlı negatif, doğrusal ve zayıf bir ilişki vardır. Yüzeysel davranışlar ile yaşam doyumu arasında $(\mathrm{r}=-0,050, \mathrm{p}>0,05)$ istatistiksel olarak anlamlı bir ilişki, pozitif duygulanım arasında $(\mathrm{r}=-0,118, \mathrm{p}>0,05)$ i istatistiksel olarak anlamlı bir ilişki, negatif duygulanım arasında $(r=0,101, p>0,05)$ istatistiksel olarak anlamlı ilişki yoktur. Derin davranışlar ile samimi davranışlar arasında $(\mathrm{r}=0,193, \mathrm{p}<0,01)$ istatistiksel olarak anlamlı pozitif, doğrusal ve zayıf bir ilişki vardır. Derin davranışlar ile yaşam doyumu arasında ( $\mathrm{r}=-$ $0,014, p>0,05$ ) istatistiksel olarak anlamlı bir ilişki, pozitif duygulanım arasinda $(r=-0,096, p>0,05)$ istatistiksel olarak anlamlı bir ilişki, negatif duygulanım arasında $(\mathrm{r}=0,102, \mathrm{p}>0,05)$ istatistiksel olarak anlamlı ilişki yoktur.

Tablo 3. Tüm Değişkenler Arasındaki İlişkiler

\begin{tabular}{|c|c|c|c|c|c|c|c|}
\hline DEĞİSSENLER $(\mathrm{n}=235)$ & & 1 & 2 & 3 & 4 & 5 & 6 \\
\hline 1-Yüzeysel Davranışlar & $\mathrm{r}$ & 1 & & & & & \\
\hline \multirow{2}{*}{ 2-Derin Davranışlar } & $\mathrm{r}$ &, $379^{* *}$ & \multirow{2}{*}{-1} & & & & \\
\hline & $\mathrm{p}$ & 000 & & & & & \\
\hline \multirow{2}{*}{ 3-Samimi Davranışlar } & $\mathrm{r}$ &,$- 144^{*}$ & $193^{* *}$ & 1 & & & \\
\hline & $\mathrm{p}$ & ,027 & ,003 & & & & \\
\hline \multirow{2}{*}{ 4-Yaşam Doyumu } & $\mathrm{r}$ &,- 050 & ,014 & 127 & 1 & & \\
\hline & $\mathrm{p}$ & 449 & 825 & ,052 & & & \\
\hline \multirow{2}{*}{ 5-Pozitif Duygulanım } & $\mathrm{r}$ &,- 118 & 096 &, $188^{* *}$ & $225^{* *}$ & 1 & \\
\hline & $\mathrm{p}$ &, 070 & , 140 & ,004 & , 001 & & \\
\hline \multirow{2}{*}{ 6-Negatif Duygulanım } & $\mathrm{r}$ & ,101 & ,102 &,- 114 & , 025 &,- 007 & 1 \\
\hline & $\mathrm{p}$ & 122 & 117 & ,081 & ,707 & ,918 & \\
\hline
\end{tabular}

${ }^{* *} r 0,01$ anlamlllık düzeyinde, ${ }^{*} r$ 0,05 anlamlllı düzeyinde

Samimi davranışlar ile pozitif duygulanım arasında $(r=0,188, p<0,01)$ istatistiksel olarak anlamlı pozitif, doğrusal ve zayıf bir ilişki vardır. Samimi davranışlar ile yaşam doyumu arasında $(r=-0,127, p>0,05)$ istatistiksel olarak anlamlı bir ilişki ve negatif duygulanım arasında $(r=-0,114, p>0,05)$ istatistiksel olarak anlamlı ilişki yoktur. Yaşam doyumu ile pozitif duygulanım ara- 
sinda $(\mathrm{r}=0,225, \mathrm{p}>0,01)$ istatistiksel olarak anlamlı pozitif, doğrusal ve zayıf bir ilişki elde edilmiştir. Yaşam doyumu ile negatif duygulanım arasında $(\mathrm{r}=-0,025, \mathrm{p}>0,05)$ istatistiksel olarak anlamlı bir ilişki yoktur. Pozitif duygulanım ile negatif duygulanım arasında $(\mathrm{r}=-0,007, \mathrm{p}>0,05)$ istatistiksel olarak anlamlı ilişki yoktur. bu açıklamalarda korelasyon katsayılarındaki ifadeleri özetleyecek olursak öznel iyi oluşun ve duygusal emeğin alt boyutlarının birbirleriyle ilişkili olması beklenen bir sonuçtur. Araştırmamızın hipotezleri açısından ise hipotezlerimizi destekleyen sadece öznel iyi oluş alt boyutlarından pozitif duygulanım ile duygusal emeğin alt boyutlarından samimi davranış arasında istatistiksel olarak anlamlı pozitif, doğrusal ve zayıf bir ilişkinin olması araştırmamızın en önemli sonucudur.

\section{Değişkenler Arasındaki Etki Analizleri}

Değişkenler arasındaki ilişki analizleri sonrasında basit regresyon analizi yapılmıştır. Araştırmanın onuncu, hipotezi kapsamında yaşam doyumunun samimi davranış üzerindeki etki durumu incelenmiştir. Bu duruma yönelik yapılan basit regresyon analiz sonuçları değerlendirilmiş ve çeşitli yorumlarda bulunulmuştur.

Tablo 4. Yaşam Doyumunun Samimi Davranışa Etki Analizi Tablosu

\begin{tabular}{llllll}
\hline Değişken & $\mathrm{B}$ & Standart hata & Beta & $\mathrm{T}$ & $\mathrm{p}$ \\
\hline Sabit & 3,777 &, 188 & 20,061 &, 000 \\
Yaşam Doyumu &, 086 &, 044 &, 127 & 1,953 &, 050 \\
\hline $\mathrm{N}=235, \mathrm{R}=0,127, \mathrm{R}^{2}=0,016$, Düzel. & $\mathrm{R}^{2}=0,012, \mathrm{~F}=3,814, \mathrm{p}<0,05$ \\
\end{tabular}

Yaşam doyumu toplam varyansın \%1,6'sını açıklamaktadır. Standardize edilmiş beta katsayısı ve $t$ değerleri incelendiğinde yaşam doyumunun samimi davranmayı anlamlı bir şekilde etki ettiği söylenebilir $(t=1,953$, $\mathrm{p}<, 05)$. Bu durumda da kurulan modelinde anlamlı olduğu görülmüştür $(\mathrm{F}=3,814, \mathrm{p}<0,05)$.

Araştırmanın on birinci hipotezi kapsamında olumlu duygulanımın samimi davranış üzerindeki etki durumu incelenmiştir. Bu duruma yönelik olarak yapılan basit regresyon analiz sonuçları değerlendirilmiş ve yorumlar yapılmıştır. 
Tablo 5. Olumlu Duygulanımın Samimi Davranışa Etki Analizi Tablosu

\begin{tabular}{llllll}
\hline Değişken & B & Standart hata & Beta & T & p \\
\hline Sabit & 3,355 &, 271 & & 12,375 &, 000 \\
Olumlu Duygulanim &, 239 &, 082 &, 188 & 2,915 &, 004 \\
\hline $\mathrm{N}=235, \mathrm{R}=0,188, \mathrm{R}^{2}=0,035$, Düzel. $\mathrm{R}^{2}=0,031, \mathrm{~F}=8,499, \mathrm{p}<0,01$ & &
\end{tabular}

Olumlu duygulanım toplam varyansın \%3,5'ini açıklamaktadır. Standardize edilmiş beta katsayısı ve $t$ değerleri incelendiğinde olumlu duygulanımın samimi davranışı anlamlı bir şekilde etkilediği söylenebilir $(\mathrm{t}=2,915, \mathrm{p}<, 01)$. Kurulan modelinde anlamlı olduğu görülmektedir $(\mathrm{F}=8,499, \mathrm{p}<0,01)$.

\section{Hipotezlerin Kabul-Red Durumlan}

Araştırmanın hipotezlerine ait kabul -red sonuçları tablo 6 da sunulmuştur.

Tablo 6. Hipotezlerin sonuçları

\begin{tabular}{|c|c|c|c|c|}
\hline & Hipotezler & $\mathrm{R} / \mathrm{B}$ & sig. & Sonuç \\
\hline $\mathrm{H}_{1}$ & $\begin{array}{l}\text { Yaşam doyumu ile yüzeysel davranış arasında anlamlı } \\
\text { bir ilişki bulunmaktadır. }\end{array}$ &,- 050 & $\mathrm{P} \gg, 05$ & Red \\
\hline $\mathrm{H}_{2}$ & $\begin{array}{l}\text { Yaşam doyumu ile derin davranış arasında anlamlı bir } \\
\text { ilişki bulunmaktadır. }\end{array}$ & ,014 & $\mathrm{P} \gg, 05$ & Red \\
\hline $\mathrm{H}_{3}$ & $\begin{array}{l}\mathrm{H}_{3} \text { : Yaşam doyumu ile samimi davranış arasında } \\
\text { anlamlı bir ilişki bulunmaktadır. }\end{array}$ & ,127 & $\mathrm{P}<, 05$ & Kabul \\
\hline $\mathrm{H}_{4}$ & $\begin{array}{l}\text { H4: Olumlu duygulanım ile yüzeysel davranış arasın- } \\
\text { da anlamlı bir ilişki bulunmaktadır. }\end{array}$ &,- 118 & $\mathrm{P} \gg, 05$ & Red \\
\hline $\mathrm{H}_{5}$ & $\begin{array}{l}\text { H5: Olumlu duygulanım ile derin davranış arasında } \\
\text { anlamlı bir ilişki bulunmaktadır. }\end{array}$ & ,096 & $\mathrm{P} \gg, 05$ & Red \\
\hline $\mathrm{H}_{6}$ & $\begin{array}{l}\text { H6: Olumlu duygulanım ile samimi davranış arasında } \\
\text { anlamlı bir ilişki bulunmaktadır. }\end{array}$ & ,188 & $\mathrm{P}<, 01$ & Kabul \\
\hline $\mathrm{H}_{7}$ & $\begin{array}{l}\text { H7: Olumsuz duygulanım ile yüzeysel üzerinde ara- } \\
\text { sında anlamlı bir ilişki bulunmaktadır. }\end{array}$ & ,101 & $\mathrm{P}>, 05$ & Red \\
\hline $\mathrm{H}_{8}$ & $\begin{array}{l}\text { H8: Olumsuz duygulanımın ile derin davranış arasın- } \\
\text { da anlamlı bir ilişki bulunmaktadır. }\end{array}$ & ,102 & $\mathrm{P} \gg, 05$ & Red \\
\hline $\mathrm{H}_{9}$ & $\begin{array}{l}\text { H9: Olumsuz duygulanımın ile samimi davranış ara- } \\
\text { sında anlamlı bir ilişki bulunmaktadır. }\end{array}$ &,- 114 & $\mathrm{P} \gg, 05$ & Red \\
\hline $\mathrm{H}_{10}$ & $\begin{array}{l}\text { H10: Yaşam doyumunun samimi davranış üzerinde } \\
\text { anlamlı bir etkisi bulunmaktadır. }\end{array}$ & ,086 & $\mathrm{P}<, 05$ & Kabul \\
\hline $\mathrm{H}_{11}$ & $\begin{array}{l}\text { H11: Olumlu Duygulanımın samimi davranış üzerinde } \\
\text { anlamlı bir etkisi bulunmaktadır. }\end{array}$ & ,239 & $\mathrm{P}<, 05$ & Kabul \\
\hline
\end{tabular}




\section{Sonuç ve Tartışma}

Yapılan analizler ve hipotezlerin red / kabul durumları incelendiğinde yaşam doyumu ve samimi davranış, olumlu duygulanım ve samimi davranış arasında ilişki ve etkileşim olduğu görülmektedir diğer değişkenler arası anlamlı bir ilişki bulunamamıştır literatürde Kızanıklı, (2014, s. 61) tarafından yapılan çalışmada bağımsız değişkenler olan olumlu ve olumsuz duygu durumları algıları ile bağımlı değişken olan duygusal emek davranışı arasında pozitif yönlü ilişki olduğu durumunu destekler niteliktedir. Ayrıca Savaş (2012) tarafından yapılan araştırmada okul yöneticilerinin duygusal emek yeterliliklerinin öğretmenlerin iş doyumlarını anlamlı bir şekilde yordadığını saptamıştır sonucu ile de doğru orantılıdır denebilir. Bilindiği gibi öznel iyi oluş mutluluğu ve/veya iş yaşamında mutluluğu da tanımlamaktadır. Bu açıdan bakıldığında ise Özmen ve Apalı (2018, s.281) yapmış olduğu araştırmada duyguların bastırılması ile işyeri mutluluğu arasında pozitif yönlü anlamlı bir ilişki tespit ederken derin davranış ile işyeri mutluluğu arasında pozitif yönlü anlamlı bir ilişki tespit etmişlerdir. Bu durum ise bu çalışmanın sonuçlarına uyum sağlamamıştır.

Öznel iyi oluşun alt boyutlarından olan olumsuz duygulanım isminden de anlaşılacağı üzere kişilerin mutsuz ve depresif olduğu gerçeğini yansitmaktadır bu durum da doğal olarak duygusal emek davranışın olumlu yönde etkilememektedir. Bir başka deyişle mutsuz olan kişiler iş yerinde gösterilmesi gereken duygu durumların istenilen şekilde göstermemektedir. Her ne kadar hipotezler red olunsa da bu durum kavramsal olarak doğru kabul edilebilir.

Olumlu duygulanım durumu ise kişilerin mutlu neşeli olduğu durumlardır, araştırmadaki hipotezlerde bu durumun red olunması araştırmada şaşırtıc bir şekilde beklenmedik bir sonuç olarak karşımıza çıkmaktadır. Bu çelişkili durum hakkında sağlık sektöründe daha geniş örneklemle, farklı sektör ve gruplarda da araştırılarak belirsizliğin giderilebileceği değerlendirilmektedir.

Sonuç olarak öznel iyi oluş ve alt boyutları ve duygusal emek davranışı alt boyutları değişkenleri ile farklı çalışma gruplarında çalışmaların yapılması bu konu hakkında bilgilendirmeler ve eğitimler verilmesi ve sektörün farkında lığının ve bilgi seviyelerinin artması başta sağlık çalışanları olmak üzere yöneticileri olumlu yönde etkileyeceği değerlendirilmektedir. 


\title{
EXTENDED ABSTRACT
}

\section{The Effect of Subjective Well-Being on Emotional Labor in Healt Employees}

\author{
Bünyamin Özgüleş - Ali Arslanoğlu \\ Yunus Emre Hospital, Health Science University
}

Like all people, health workers can react differently to stimuli, both in private life and in business life, and exhibit different behavioral situations. This phenomenon is largely due to the general life satisfaction and positive, negative emotional states of human beings, as well as the subjective goodness of the work that occurs at work. At every stage of the presentation of health services where the emotional state of the employees is important, the subjective well-being and emotional labor levels of the health workers are effective. More generally, employees with high levels of subjective well-being are expected to show the emotional labor behaviors that the institutions want more prominently and as desired. One of the main objectives of this research is to examine the relationship and impact levels between these two variables. In this context, it is thought that increasing the awareness levels of employees and managers on these issues will have a positive impact on the health of the employees, their success and therefore the quality of service they exhibit in the workplaces. Within the framework of this information, in this study, in the sample of private hospital employees operating in Ankara, examining the level of subjective wellness and emotional labor levels of health workers and the relationship and impact status between these two variables are the main objectives of the study. In this context, the aim of the study; to investigate the effect of sub-dimensions of subjective well-being on sub-dimensions of emotional labor in more detail. For this purpose, two-stage research was designed. First, exploratory research was conducted to understand the subjects of concepts. In the second stage, answers were sought for questions in scale items. The findings were analyzed through various statistical software. The research universe consists of staff working in a private hospital in Ankara. All employees were tried to be reached by the total population sampling method without the 
selection of samples. 413 people in private hospitals were reached, but 250 people agreed to participate in the study, and they were included in the study. 15 of the questionnaire forms given for answering were removed with the idea that they were incomplete and biased, and 235 questionnaires were included in the survey. Method: In this stage of the study, information about the variables, model, universe and sample status, hypotheses of the research and data collection technique were included. In the study, it was aimed to test and develop a theoretical model that the sub-dimensions of subjective well-being affect the subdimensions of emotional labor. The independent variables of the study consisted of life satisfaction, positive emotions and negative emotions variables that measure the effects of subjective well-being. The dependent variable of the research is sincere acting, deep acting and surface acting, which are the sub-dimensions of emotional labor. In the research, the data obtained from the questionnaires are analyzed by using a relational scanning method and as a result, various suggestions will be made to the managers and employees according to the realization of the hypotheses. The questionnaire consisted of items of early writing to inform participants about the research and including informed consent. In the first part, 6 items are covering the socio-demographic characteristics of the participants, in the second part there are 25 items related to subjective well-being and in the third part, there are 13 items related to emotional labor. Subjective Well-being Scale; Since subjective well-being consists of two components, cognitive and emotional, two scales are used in the measurement. The first is the life satisfaction scale. The second is the positive-negative affect scale. The Life Satisfaction Scale was developed by Diener et al. (1985) and adapted to Turkish by Köker (1991). The Positive-Negative Emotion Scale was developed by Watson et al. (1988) and adapted to Turkish by Gençöz (2000). Emotional Labor Scale, developed by Diefendorff, Croyle and Gosserland (2005, p.339-340) and adapted to Turkish by Basim and Begirbas (2012, p.77), will be used to evaluate the emotional labor of the employees. The scale consists of three subdimensions: superficial role-playing sub-dimension (6 items1-6 questions), deeply acting role-sub dimension (4 items 7-10 questions) and intimate feelings sub-dimension (3 items 11-13 questions). When the rejection/acceptance status of the analyzes and hypotheses are examined, 
it is seen that there are a relationship and interaction between life satisfaction and sincere behavior, positive affect and sincere behavior. No significant relationship was found between the other variables. The findings support the study in the literature conducted by Kizanıklı (2014, p.61) the positive relationship between independent variables, positive and negative emotions, and dependent variable, emotional labor behavior. It can also be stated that these results are on the same axis with the result of the research conducted by Savaş (2012) that the emotional labor competencies of school administrators significantly affect the job satisfaction of teachers. As it is known, subjective well-being defines happiness and / or happiness in business life. In this respect, in the study conducted by Özmen and Apalı (2018, p.281), a positive and significant relationship was found between suppression of emotions and workplace happiness, while a positive relationship was found between deep behavior and workplace happiness. This situation did not comply with the results of this study. Negative affect, which is one of the sub-dimensions of subjective well-being, reflects the fact that people are unhappy and depressed as the name implies. This situation naturally does not affect emotional labor behavior positively. In other words, unhappy people do not show the emotions that should be shown at work as desired. Although hypotheses are not supported, this can be considered conceptually correct. On the other hand, positive affective situations are situations where people are happy and cheerful. The fact that the hypotheses in the study did not support this was surprisingly unexpected in the study. It is evaluated that uncertainty can be eliminated by investigating this contradictory situation in different sectors and groups. As a result, it will be meaningful to evaluate the sub-dimensions of subjective well-being and the subdimensions of emotional labor behavior in different groups. Besides, it is considered that providing information and training on the subject and increasing the awareness and knowledge level of the sector will positively affect the managers, especially health workers.

\section{Kaynakça / References}

Akdoğan, A. ve Polatçı, S., (2013). Psikolojik sermayenin performans üzerindeki etkisinde iş aile yayılımı ve psikolojik iyi oluşun etkisi. Atatürk Üniversitesi Sosyal Bilimler Enstitüsü Dergisi 17(1), 273-293. 
Ashforth, B. E. ve R. H. Humphrey. (1993). Emotional Labor in Service Roles: The Influence ofIdentity. Academy of Management Review, 18(1), 88-115.

Basım, H. N., Begenirbaş, M., (2012). Çalışma yaşamında duygusal emek: Bir ölçek uyarlama çalışması. Yönetim Ve Ekonomi 19(1), 78.

Beğenirbaş, M ve Basım, N. (2013). Duygusal emekte bazı demografik değişkenlerin rolü.Çankaya University Journal of Humanities and Social Sciences, 10(1), 45-57.

Diefendorff, J. M., Croyle, M. H., ve Gosserand, R. H. (2005). The dimensionality and antecedents of emotional labor strategies. Journal of Vocational Behavior, 66(2), 339-357. doi: http://dx.doi.org/10.1016/j.jvb. 2004.02.001.

Diener, E. (1984). Subjective well-being. Psychological Bulletien, 95, 542-575.

Diener, E., Emmons, R. A., Larsen, R. J. ve Griffin, S. (1985). The satisfaction with lifescale. Journal of Personality Assessment, 49, 71-75.

Doğan, T., Eryılmaz, A. (2012). Akademisyenlerde işle ilgili temel ihtiyaç doyumu ve öznel iyi oluş. Ege Akademik Bakış, 12(3), 383-389.

Gençöz, T. (2000). Pozitif ve negatif duygu ölçeği: Geçerlik ve güvenirlik çalışması. Türk Psikoloji Dergisi, 15(46), 19-26.

Grandey, A. (2003). When the show must go on: Surface acting and deep acting as determinants of emotional exhaustion and peer-rated service delivery. Academy of Management Journal, 46, 86-96.

Grandey, A.A. (2000). Emotion regulation in the workplace: A new way to conceptualize emotional labor. Journal of Occupational Health Psycho$\log y, 5(1), 95-110$.

Hochschild, A.R. (1983). The managed heart: The commercialization of human feeling. University of California Press, Berkeley, 7-38.

Keçeli, S. (2019). "Sinizm" sağlık kurumlarında örgütsel davranış. Arslanoğlu, A. (Ed.), Ankara: Nobel Akademik Yayıncılık.

Kızanıklı, M.M. (2014). Otel işletmelerinde duygusal emek öncüllerinin belirlenmesine yönelik bir araştırma. Yayınlanmamış Doktora Tezi, Gazi Üniversitesi. Eğitim Bilimleri Enstitüsü, Ankara.

Köker, S., (1991). Normal ve sorunlu ergenlerin yaşam doyumu düzeyinin karşılaştırılması. Yayınlanmamış Yüksek Lisans Tezi, Ankara Üniversitesi Sosyal Bilimler Enstitüsü, Ankara.

Kruml, S.M. ve D. Geddes (2000). Exploring the dimensins of emotional labor: The heart of hoschshild's work. Management Comunication Quarterly, 14, 8-49. 
Morris, J.A. ve Feldman, D.C. (1996). The dimensions, antecedents and consequences of emotional labor. Academy of Management Review, 21(4), 986-1010.

Myers, D. ve Deiner, E. (1995). Who is happy. American Psychological Society, 6(1),1-19.

Özmen. M.. ve Apalı, A. (2018)., Muhasebe meslek elemanlarında duygusal emek ve işyeri mutluluğu ilişkisi: Burdur örneği. Selçuk Üniversitesi Sosyal Bilimler Meslek Yüksekokulu Dergisi, 21(2), 274-283.

Polatçı, S. ve Özyer, K. (2015). Duygusal emek stratejilerinin duygusal zekanın tükenmişliğe etkisindeki aracılık rolü. AİBய̈ Sosyal Bilimler Enstitüsü Dergisi, 15(3), 131-156.

Uzuntarla, Y. (2015). Kişilik özellikleri ile empatik özellikler arasındaki ilişkide duygusal emek ve tükenmişliğin aracılık rolü: Hekimler üzerine bir araştırma. Yayınlanmamış Doktora Tezi, GATA, Ankara.

Savaş, A.C. (2012). İlköğretim okul müdürlerinin duygusal zekâ ve duygusal emek yeterliklerinin öğretmenlerin iş doyumuna etkisi. Yayımlanmamış Doktora Tezi, Gaziantep Üniversitesi Sosyal Bilimler Enstitüsü, Gaziantep.

Savaş, A. C. (2012). Okul müdürlerinin duygusal zekâ ve duygusal emek yeterliklerinin öğretmenlerin iş doyumu düzeylerine etkisi. Dumlupinar Üniversitesi Sosyal Bilimler Dergisi, 33, 139-148.

Seçer, Ş. (2005). Çalışma yaşamında duygular ve duygusal emek: Sosyoloji, psikoloji ve örgüt teorisi açısından bir değerlendirme. İktisat Fakültesi Sosyal Siyaset Konferansları, Prof. Dr. Nevzat Yalçıntaş'a Armă̆an Özel Sayısı, 50. Kitap, İstanbul: İÜ Yayınevi, (813-834).

Watson, D., Clark, L.A. ve Tellegen, A. (1988). Development and validation of brief measure of positive and negative affect: The PANAS Scales. Journal of Personality and Social Psychology, 54(6), 1063-1070.

Yalçın, A. (2010). Emotional labor: Dispositional antecedents and the role of affective events. Yayınlanmamış Yüksek Lisans Tezi, ODTÜ, Ankara.

Yazıcıoğlu, Y. ve Erdoğan, S. (2014). SPSS uygulamalı bilimsel araştırma yöntemleri. (4.bask1). Ankara: Detay Yayıncılık.

\section{Kaynakça Bilgisi / Citation Information}

Özgüleş, B. ve Arslanoğlu, A. (2020). Sağlık çalışanlarında öznel iyi oluşun duygusal emek davranışı üzerine etkisi. OPUS-Uluslararası Toplum Araştırmaları Dergisi, 15(22), 1114-1133. DOI: 10.26466/opus.663474 